\title{
Experimental investigation on the emission reduction potential of metal oxide- coated ceramic foam filters as substrates for diesel engines
}

\author{
M. Premnath ${ }^{1 *}$ and G. Murugan ${ }^{2}$ \\ Research Scholar, Department of Mechanical Engineering, Faculty of Engineering and Technology, Annamalai \\ University, Tamilnadu - 608002, India ${ }^{1}$ \\ Professor, Department of Mechanical Engineering, Faculty of Engineering and Technology, Annamalai University, \\ Tamilnadu - 608002, India ${ }^{2}$
}

Received: 01-June-2021; Revised: 19-August-2021; Accepted: 20-August-2021

(C)2021 M.Premnath and G.Murugan. This is an open access article distributed under the Creative Commons Attribution (CC BY) License, which permits unrestricted use, distribution, and reproduction in any medium, provided the original work is properly cited.

\begin{abstract}
The applicability of ceramic foam filter as a honeycomb structure substitute to achieve a reduction in the amount of engine exhaust emitted from a diesel engine at various brake powers is tested and studied experimentally. Initially, ceramic foam filters were wash-coated in-house using metal oxides such as Aluminum Oxide $\left(\mathrm{Al}_{2} \mathrm{O}_{3}\right)$, Copper Oxide (CuO), and Titanium Oxide $\left(\mathrm{TiO}_{2}\right)$. The wash-coated ceramic foams were installed inside the outer casing of the Catalytic Converter (CC), which was fabricated in-house according to the dimensions of the CC manufactured by the Original Equipment Manufacturer (OEM). The CC manufactured by OEM consists of honeycomb monolith wash-coated with Platinum (Pt), Palladium (Pd), and Rhodium $(R h)$ as catalyst materials. The initial performance and emission tests were conducted using the manufactured CC. Following this, the experiments were conducted using ceramic foam-modified CC. The experimental results show that the brake thermal efficiency exhibited by the ceramic foam filter was less than that recorded for the honeycomb monolith substrate. At full load, the Brake Thermal Efficiency (BTE) of the OEM manufactured CC, ceramic foam filter-wash coated with $\mathrm{Al}_{2} \mathrm{O}_{3}, \mathrm{CuO}$, and $\mathrm{TiO}_{2}$, were $33.14 \%, 31.6 \%, 30.2 \%$, and $29.2 \%$, respectively. Reduced emission output parameters, such as Hydrocarbon (HC), Carbon Monoxide (CO), and Oxides of Nitrogen (NO $\mathrm{O}_{x}$ emissions, were recorded for the metal oxide-coated ceramic foam filter. The $\mathrm{CO}$ and $\mathrm{HC}$ conversion efficiencies observed for the ceramic foam filter were significantly higher than the efficiencies of the CC manufactured by OEM. The NOx conversion efficiency was marginally higher than that recorded for the manufactured $C C$.
\end{abstract}

\section{Keywords}

Ceramic foam filter, Honeycomb monolith, Metal oxides, Performance, Emission.

\section{Introduction}

In the field of road transportation, the majority of the vehicles are powered either by diesel or gasoline engines. These engines are fuelled using fossil fuel, resulting in carbon monoxide, unburned hydrocarbon, nitrogen oxides, and soot emission. The emissions from these engines-powered vehicles are one of the major contributors to environmental pollution [1]. The emission from road transport vehicles accounts for two-thirds of the total emissions recorded from the transportation sector [2].

Diesel-based engines are widely used in buses, heavy trucks, commercial light-duty vehicles, and passenger cars.

*Author for correspondence 1033
They exhibit higher torque, load-carrying capacity, thermal efficiency, and low maintenance cost compared to gasoline-based engines [3].

On the other hand, diesel-powered vehicles emit higher amounts of toxic gases compared to gasolinepowered vehicles [4]. The extent of air pollution caused by the emissions from these vehicles is continuously increasing as the demand for vehicles is increasing with time to meet the requirements of the ever-growing population [5].

The emissions adversely affect the environment, resulting in climatic changes. Human health is also adversely affected by toxic emissions [6]. To control the pollution caused by vehicles, pollution control authorities laid out emission norms (revised once every five years) to cut down the levels of vehicular 
emission to a certain limit [7]. In the year 2020, most of the countries have rejected the EURO IV norms and implemented the EURO VI. The EURO VI norms are very stringent compared to the EURO IV norms (especially for diesel engine-based vehicles) [8]. This imposes a greater challenge on the automobile manufacturers and researchers to keep the vehicular emissions within acceptable limits under various driving conditions. Emissions from diesel-based vehicles can be controlled by improving the engine design, combustion efficiency, and exhaust gas treatment devices. Different techniques are used to reduce the extent of vehicular emission. The methods include the treatment of exhaust gases, controlling the operating parameters, tuning the parameters, and incylinder combustion control [9]. New ideas to upgrade the technologies used for the development of engines and engine concepts to control emission are rarely being researched at present [10]. The field has reached a saturation point. As a result of this, researchers are showing more interest in upgrading the existing devices or development new after-treatment devices to control the emissions. This involves developing new catalyst materials, designing new Catalytic Converter (CC) substrates, and tuning the material properties.

The diesel engine-based vehicles are equipped with after-treatment devices to control the emission of toxic substances. These after-treatment devices use a honeycomb-shaped ceramic substrate as a filter. This filter is coated with expensive noble catalyst materials such as $\mathrm{Pt}, \mathrm{Pd}$, and $\mathrm{Rh}$, for the oxidation and reduction of toxic emissions. The drawbacks of the currently used honeycomb monolith filters are [11]:

- The flow of exhaust gases across the monolith is uneven, i.e., most of the gases, flow through the center of the monolith, whereas the outer periphery of the monolith remains unused. This results in the underperformance of the honeycomb monolith.

- There is a lack of thermal homogeneity across the monolith. As the flow inside the honeycomb monolith is laminar, and most gases flow through the center, a high-temperature zone is observed at the center. The temperature of the central region is higher than the temperature of the outer region. This leads to a faster deterioration of the central part compared to the peripheral part of the monolith.

- To address the above issues, a long monolith should be developed. An increase in the length results in an increase in the surface area. The process, however, increases the manufacturing costs. Increased amounts of expensive catalyst materials are needed for coating under these conditions. This again increases the overall cost of the unit.
- The distribution of the exhaust gases at the downstream region of the honeycomb monolith is non-homogeneous. This adversely affects the performance of the after-treatment devices present in the exhaust tailpipe. In Euro-VI guidelineconforming diesel engines, three after-treatment devices fabricated using similar honeycomb monolith substrates with different set-ups are fitted in a cascade configuration at the tailpipe.

The Empa laboratories for material science [12] have reported that ceramic foam filters possess excellent characteristics that can be exploited to overcome the drawbacks of the honeycomb-based ceramic monolith. A brief literature survey has been provided to discuss the performance of ceramic foam filters.

\section{Literature review}

Panayotis and Christian [13] and Dimopoulos et al. [14] have reported that the ceramic foam filters could be potentially used as alternatives to the conventional honeycomb substrates. They reported that foam filter exhibits better emission conversion efficiency compared to the honeycomb monolith-installed CC.

Bach and Dimopoulos [15] compared the conversion efficiencies of the Diesel Oxidation Catalyst (DOC)wash coated ceramic foam substrates and the conventional honeycomb substrates. They reported that the Carbon Monoxide ( $\mathrm{CO}$ ) and Hydrocarbon (HC) conversion efficiencies of the ceramic foam were comparable to the efficiency recorded for the honeycomb substrate, while the $\mathrm{NO}$ to $\mathrm{NO}_{2}$ conversion efficiencies were better than the efficiency exhibited by the honeycomb substrate.

Cho et al. [16] reported that the particulate matter reduction rate achieved using the Diesel Particular Filter (DPF) developed using foam filters was 59\%, which is $23 \%$ higher than that achieved using conventional DOC.

Tsinoglou et al. [17] has developed a mathematical model to study and compare the transport phenomenon between wash-coated honeycomb and ceramic foam substrates. They reported that a faster mass transfer rate in the gas phase and a slower diffusion rate through the pores of the wash coat (compared to the rates achieved using honeycomb substrates) could be achieved using ceramic foam.

Setiabudi et al. [18] reported that high soot oxidation rates could be achieved using Pt-coated ceramic foam in the presence of $\mathrm{NO}_{2}$. Researchers [19-21] also 
studied the effect of ceramic foam filters on the rate of exhaust gas flow by analyzing various parameters such as pressure drop across the foam filter and flow uniformity (downstream). Their reports revealed a uniform flow downstream and higher pressure drop (compared to the honeycomb substrate) across the ceramic foam filter.

Garrido et al. [22] investigated the impact of pore sizes and porosity of the filters on the exhaust gas mass transfer rate and drop in pressure across the filter. The results from the studies conducted by Empa [11, 12] revealed that compared to the surface of the honeycomb substrates, the surface of the foam filter was utilized more efficiently. They also claimed that the efficiency of the foam filter, half the length of a honeycomb substrate, was equal to the efficiency of the honeycomb substrate. This, in turn, reduces the material cost and use of expensive catalyst material.

The catalyst materials presently used for the fabrication of the OEM-bases $\mathrm{CC}$ is $\mathrm{Pt}$ and $\mathrm{Pd}$ (for oxidation) and $\mathrm{Rh}$ for reduction. These metals are classified as noble metals because they are resistant to chemical oxidation at high temperatures. The role of these catalysts is to increase the contact area to achieve high oxidation activity and promote the oxidation and reduction processes at a temperature that is significantly lower than the temperatures at which these processes are carried out at present [23]. These metals are regarded as precious metals, and hence the fabrication of $\mathrm{CC}$ using these metals becomes expensive. The use of rare-earth metals increases with an increase in vehicular demand. This also results in future inflation in the price of metals and vehicles. Due to this reason, the price of diesel/petrol-based vehicles might increase in the coming years [24]. To address this problem, researchers are trying to use metal oxides as catalyst materials as they are low in cost and exhibit good thermal stability [25].

Ciambelli et al. [26] reported that $\mathrm{Al}_{2} \mathrm{O}_{3}$-supported ceramic foams had shown shorter regeneration and better conversion efficiency compared to commercial foams.

Makwana et al. [27] reported that in a diesel-based engines, the $\mathrm{CO}$ emission achieved when nickel is used as a catalyst is lower than that achieved using the OEM CC fabricated with Pt or Pd as a catalyst.

Kalam et al. [28] experimentally tested metal oxides such as $\mathrm{TiO}_{2}$ and Cobalt Oxide (CoO) as catalyst materials and compared their properties with the properties of the OEM CC. They inferred that the use of $\mathrm{TiO}_{2}$ helps reduce the $\mathrm{HC}$ and $\mathrm{CO}$ emission by $40 \%$ and $41 \%$ compared to that of OEM CC. It was also found that these metal oxides exhibited light-off temperatures that were higher than those recorded for OEM catalysts.

Venkatesan et al. [29] studied the feasibility of using Copper Oxide (CuO)-based catalysts as substitutes for conventionally used $\mathrm{Pt}$ and $\mathrm{Pd}$ catalysts. It was observed that the use of $\mathrm{CuO}$-coated $\mathrm{CC}$ helped achieve better $\mathrm{HC}$ and $\mathrm{CO}$ conversion efficiencies at all load conditions, compared to OEM CC, fabricated using Pt or Pd as the catalysts.

Chauhan [30] compared the conversion efficiencies of four different metal oxides $\left(\mathrm{TiO}_{2}\right.$, Calcium Oxide $(\mathrm{CaO}), \mathrm{Al}_{2} \mathrm{O}_{3}$, and silicate kaolin) as oxidation catalysts and found that the $\mathrm{HC}$ and $\mathrm{CO}$ conversion efficiencies recorded with $\mathrm{TiO}_{2}$ were higher than those achieved using Pt and Pd catalysts. It has also been reported that these metal oxides also exhibit $\mathrm{NOx}$ reduction ability $[31,32]$.

Analysis of literature reports revealed that ceramic foam filters performed better than a honeycomb monolith in terms of emission conversion efficiency. However, limited studies are available on the engine emissions and performance characteristics of ceramic foam filters used as substrates in CC. To date, researchers have studied the performance of the ceramic foam filters using $\mathrm{Pd}, \mathrm{Pt}$, and $\mathrm{Rh}$ as catalyst materials. Studies using metal oxides as catalyst materials (in combination with ceramic foam filters) have not been reported. This research gap was addressed by us. We tested ceramic foam filters (in a diesel engine) coated with metal oxides. The performance was evaluated in terms of emission conversion efficiency and engine Brake Thermal Efficiency (BTE), and the results were compared with that of OEM's CC (3-way CC), which was installed with $\mathrm{Pd}, \mathrm{Pt}$, and $\mathrm{Rh}$ metal-coated honeycomb monolith.

The metal oxides $\mathrm{TiO}_{2}, \mathrm{Al}_{2} \mathrm{O}_{3}$, and $\mathrm{CuO}$, used for our studies, have been identified as the most potential substitutes for $\mathrm{Pt}$ and $\mathrm{Pd}$ (oxidation catalyst metals) and $\mathrm{Rh}$ (reduction catalyst metal) by analyzing literature reports. These metal oxides are easily available and cheaper than noble metals. Hence, these metal oxides were used as catalyst materials to coat the ceramic foam filters. Their influence on oxidation and reduction of toxic gases $\left(\mathrm{HC}, \mathrm{CO}\right.$, and $\mathrm{NO}_{\mathrm{x}}$ ) were also studied. 


\section{Methods}

The catalytic converter installed with metal oxidewash coated ceramic foam filter substrate was fabricated in-house. Figure 1 depicts a flow chart, which presents the outline of the procedure involved in the fabrication of the ceramic foam filter catalytic converter. The conventional methods followed for the fabrication of OEM-manufactured $\mathrm{CC}$ were used for the preparation of the catalyst slurry, coating of slurry on the foam filter, and fabrication of CC [33].

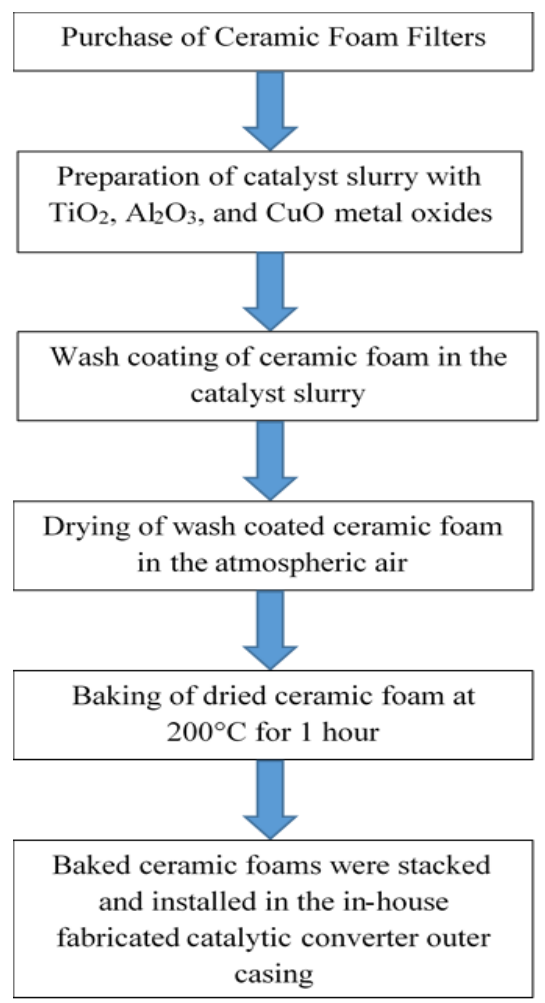

Figure 1 Procedure involved in the fabrication of the ceramic foam filter catalytic converter

\subsection{Ceramic foam filters}

The ceramic foam filters were purchased from Ceraflux India Private Limited. The foam filters were made of silica carbide. The foams were cylindrical (diameter: $40 \mathrm{~mm}$; thickness: $20 \mathrm{~mm}$ ). Six such foams were stacked following the wash coating process to obtain a ceramic foam of length $110 \mathrm{~mm}$ to match the length of the honeycomb monolith used by OEM to manufacture CC. Three such stacked ceramic foam filters were fabricated (one for each metal oxide catalyst). A ceramic foam filter with a cell density of 20 Pores per Inch (PPI) and porosity of 0.8 was used for analysis. The cell density and diameter of the honeycomb monolith manufactured by OEM were 400 Cells per Square Inch (cpsi) and $40 \mathrm{~mm}$, respectively. Figures $2 a, 2 b, 2 c$ present the honeycomb monolith, single ceramic foam filters, and stacked ceramic foam filters, respectively. For the same volume, ceramic foam filters have a lesser surface area compared to the honeycomb structure.

\subsection{Preparation of the catalyst slurry}

A slurry was prepared using a solution of sodium silicate and powdered metal oxide to wash coat the ceramic foam filters with metal oxides $\left(\mathrm{TiO}_{2} \mathrm{Al}_{2} \mathrm{O}_{3}\right.$, and $\mathrm{CuO}$ ). Sodium silicate acts as a binder and helps to bind the catalyst material to the ceramic substrate. In this process, $500 \mathrm{ml}$ of a solution of sodium silicate was taken in a glass beaker, and $10 \mathrm{~g}$ of the powdered metal oxide added to it. A small amount of distilled water as added to the mixture to lower the viscosity of the solution. The slurry was stirred continuously for 3 $\mathrm{h}$ using a magnetic stirrer. Separate slurry was prepared for each metal oxide sample. Figure 3 shows the process of slurry preparation for the wash coating process.

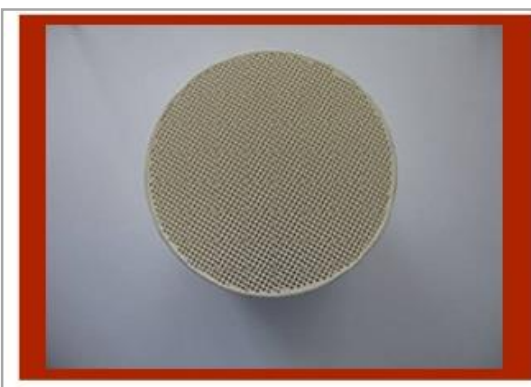

HONEY COMB MIONOLITH

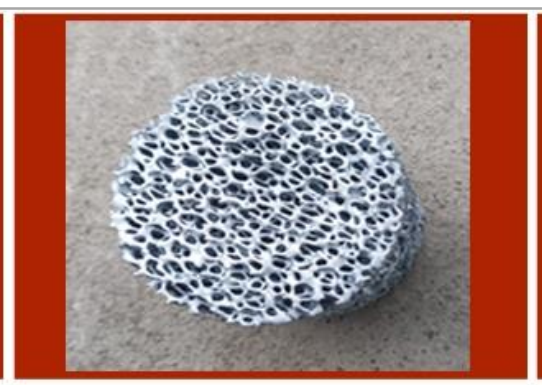

SINGIEE CEERAMIC FOAMI FILTERR

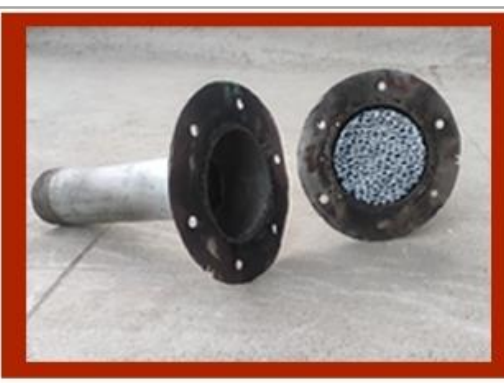

STACKED CERAMIC, FOAM FII.TER

Figure 2 a) Honeycomb monolith, b) single ceramic foam filter, and c) stacked ceramic foam filter 


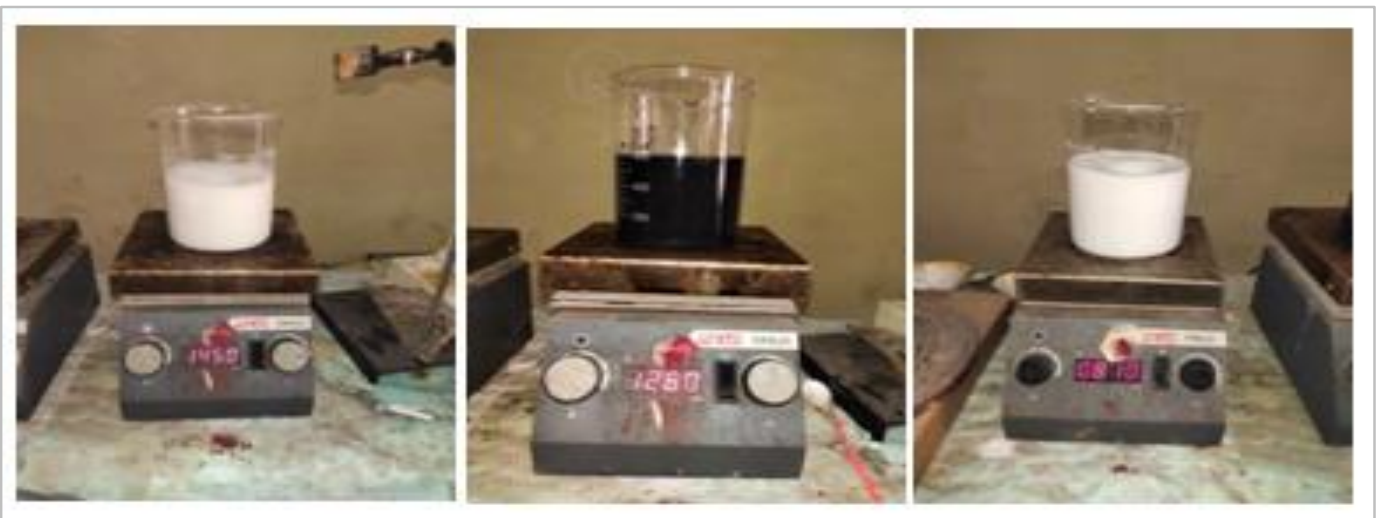

Figure 3 Preparation of metal oxide catalyst

3.3Wash coating of ceramic foam in catalyst slurry The wash coating process using ceramic foams was conducted by manually dipping the foam samples in the prepared catalyst slurry. The foam samples were held in the slurry for $2 \mathrm{~min}$. Subsequently, the foams were taken out and air-dried for $1 \mathrm{~h}$. Then pores blocked by the slurry solution were opened by carefully spraying compressed air through it without damaging the wash coat deposited on the other parts of the foams. Following this, the wash-coated ceramic foams were baked in the furnace at $200{ }^{\circ} \mathrm{C}$ for $1 \mathrm{~h}$ to fuse the coated slurry to the substrate. This process was repeated until the weight of the foams increased by approximately $15 \%$ of its base weight. Figure 4 shows the wash-coated ceramic foam filters prepared for testing.

The role of the wash coat is to increase the surface area of the substrate to achieve maximum exposure to the exhaust gas. This can help achieve high conversion efficiency. The wash coating process results in the formation of rough pores and irregular structures on the substrate. The use of metal oxide as a catalyst material helps generate active sites on the substrate on which the catalytic reaction takes place.

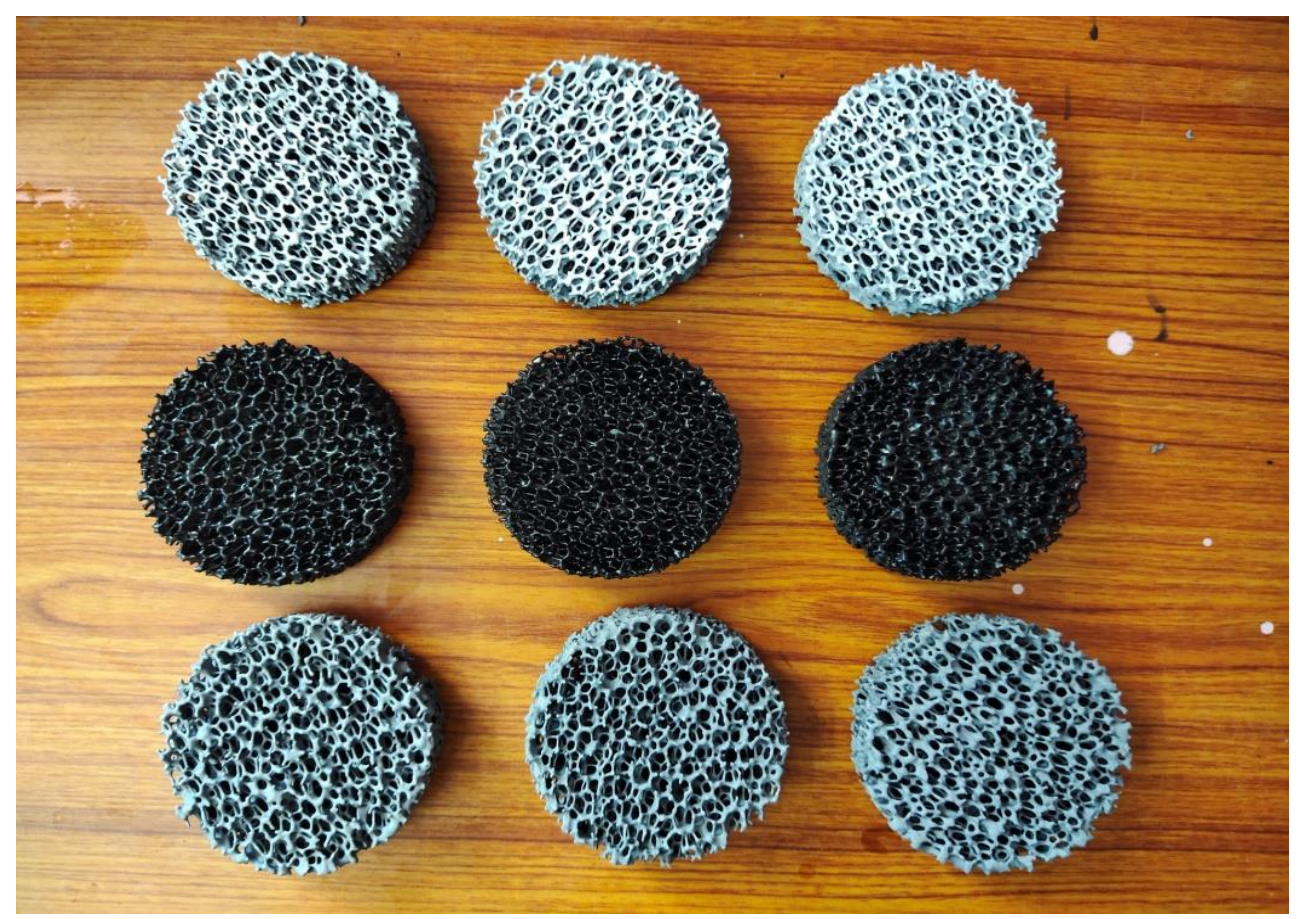

Figure 4 Wash-coated ceramic foam filters 


\subsection{CC fabrication}

The outer casing of the $\mathrm{CC}$ was fabricated in-house as per the CC dimensions reported by OEM to install the in-house fabricated wash-coated ceramic foam filters. Following this, the metal oxide wash-coated ceramic foam filter was installed in the fabricated CC. Figure
5 shows the image of the honeycomb monolithinstalled CC manufactured by the OEM. The metal oxide wash-coated ceramic foam filter was subsequently installed.

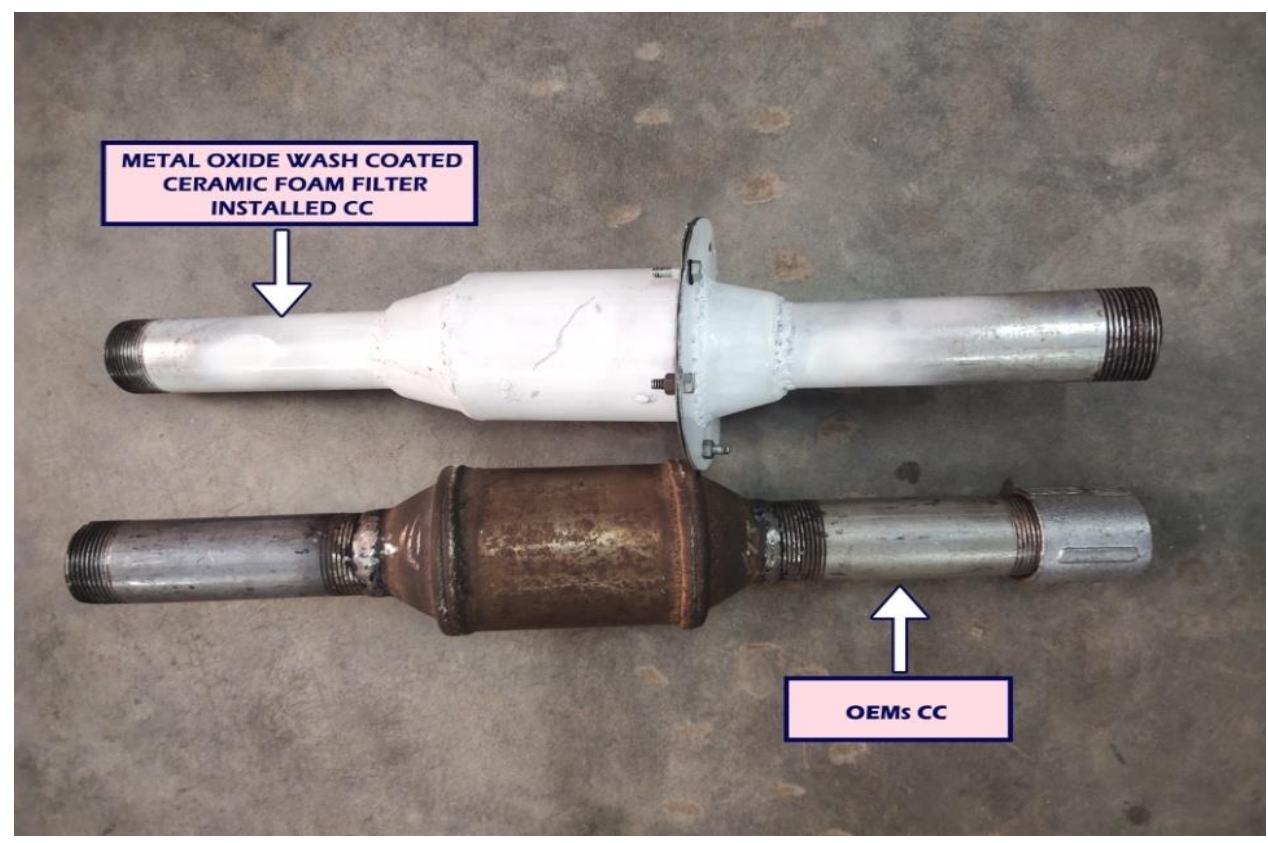

Figure 5 Images of OEM-manufactured CC and ceramic foam-installed CC

\subsection{Research engine}

We used a four-stroke-twin cylinder diesel engine (make: Mahindra) to conduct the experiments. The engine could be water-cooled. An eddy current dynamometer was connected to the engine via shafts and the process of coupling to tune the applied load on the engine. The dynamometer was loaded with the help of an S-type load cell, which was controlled electronically using a loading device. A cold water circuit surrounding the dynamometer cooled the engine by removing the heat generated during loading. The speed of the engine was maintained at $1500 \mathrm{rpm}$ under all load conditions by adjusting the accelerator pedal position, which consists of a position sensor. The accelerator was adjusted manually with the help of a rotating handwheel.

Bosh Electronic Control Unit (ECU) is provided for the Electronic Fuel Injection (EFI) system. The EFI system consists of a low and high-pressure fuel pump, a common rail, and an electronic fuel injector. The ECU controls the fuel injection quantity at various operating conditions as per the user's specified settings. In an open ECU, different parameters, such as fuel injection pressure, main injection angle, pilot injection angle, and pilot injection quantity, can be specified by the user using the "tuner pro" software. We set the fuel injection pressure at 300 bars under all the tested operating conditions. The other parameters were kept unaltered under standard settings. The fuel consumption was measured using an electronic weighing machine. An exhaust gas analyzer (make: Netel) was used to measure the $\mathrm{CO}, \mathrm{NO}_{\mathrm{x}}$, and $\mathrm{HC}$ contents in the exhaust gas. Figure 6 shows the schematic representation of the engine under study with various accessories. The engine specifications are given in Table 1. Figure 7 shows the image of the CCfitted diesel engine. 


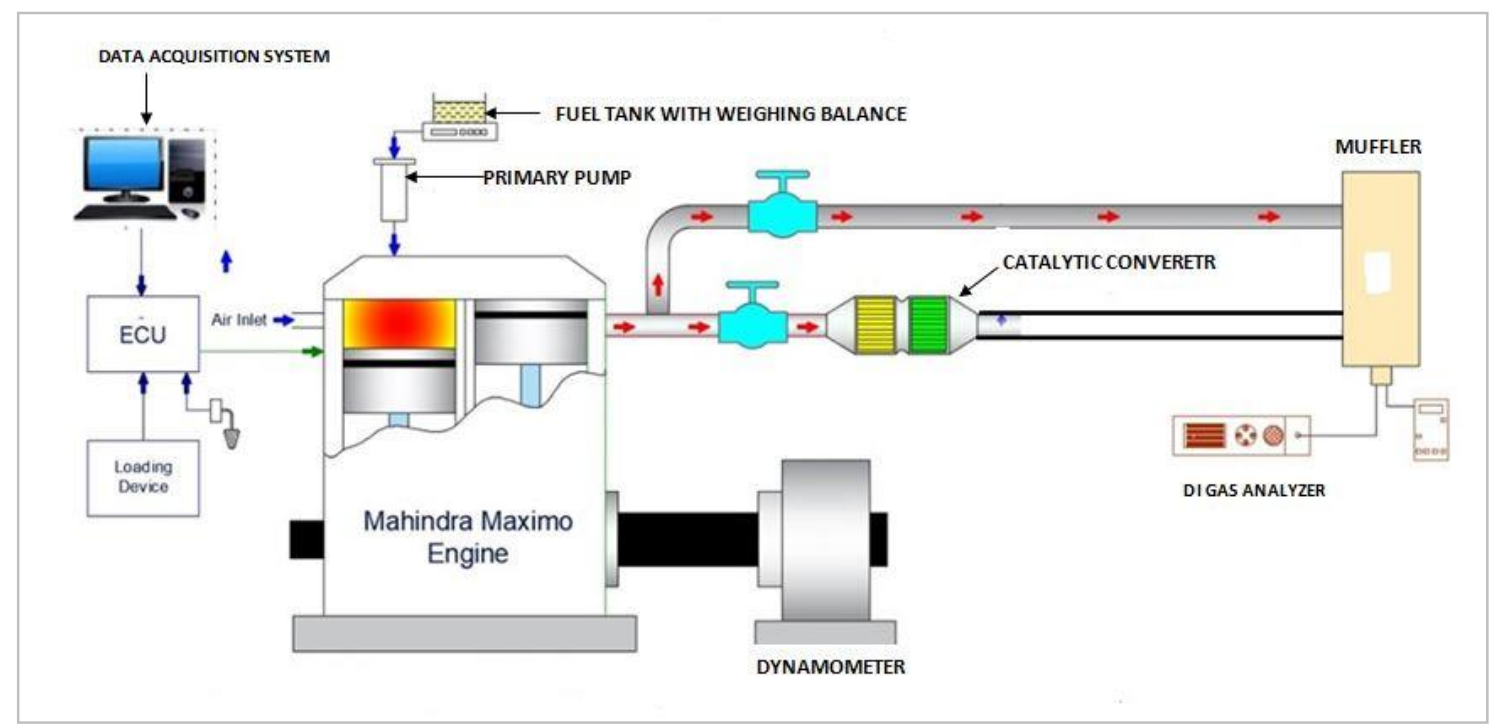

Figure 6 Schematic representation of the engine

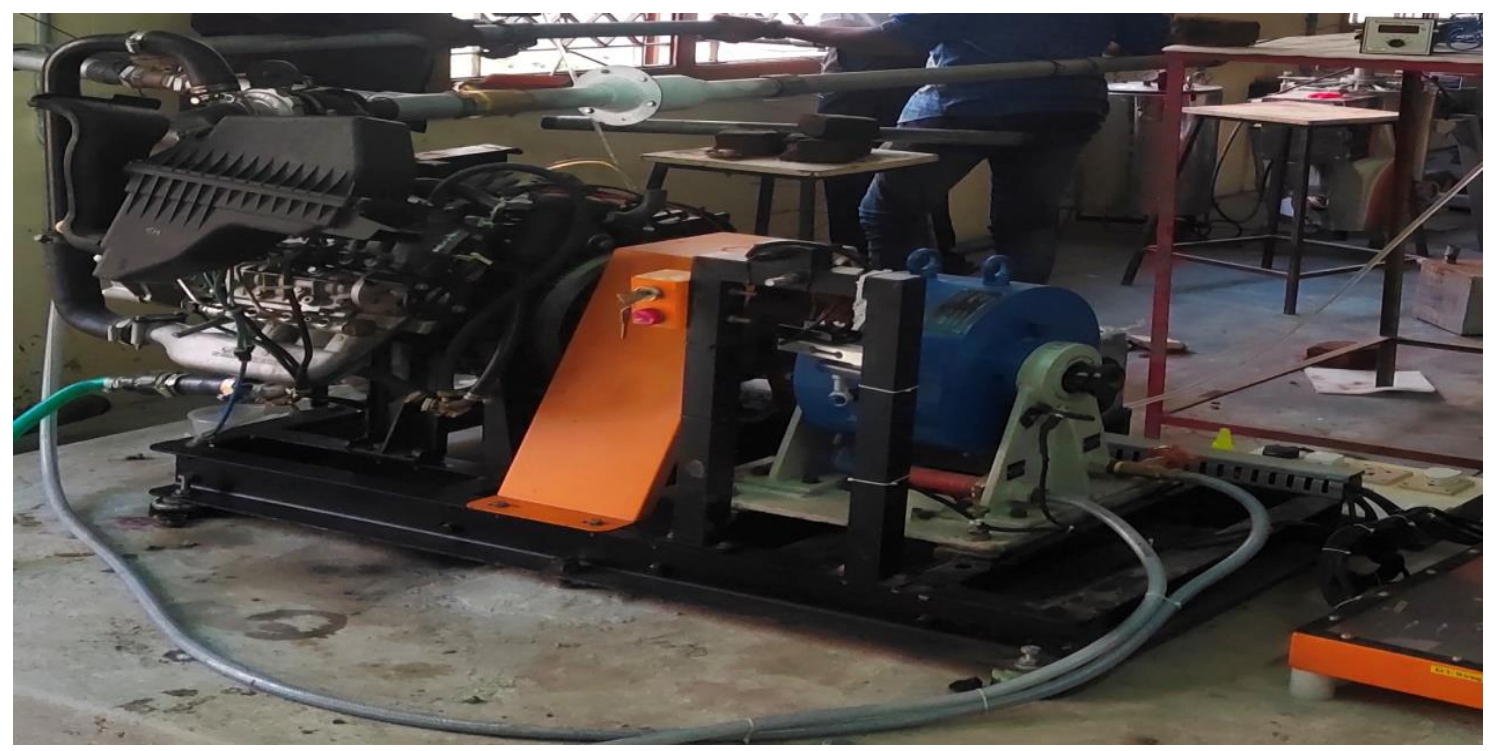

Figure 7 Image of the CC-fitted with a diesel engine

Table 1 Specification of diesel engine

\begin{tabular}{lll}
\hline S.No. & Parameters & Specification \\
\hline 1 & Make/Model & Mahindra Maximo \\
2 & Bore Diameter & $83 \mathrm{~mm}$ \\
3 & Stroke length & $84 \mathrm{~mm}$ \\
4 & Fuel Injection Type & CRDI (Common Rail Direct Injection) \\
5 & Displacement (swept Volume) & $909 \mathrm{cc}$ \\
6 & Maximum Torque & $50 \mathrm{Nm}$ \\
7 & Maximum Power & $19.2 \mathrm{~kW}$ \\
8 & Maximum Load in Dynamometer Load cell & $18 \mathrm{~kg}$ \\
9 & Fuel & Diesel \\
\hline
\end{tabular}




\subsection{Engine operating procedure}

Initially, the engine was allowed to run for $15 \mathrm{~min}$ in the presence of diesel under idling conditions. This helped the engine and the $\mathrm{CC}$ to warm up for operation. The emission tests were performed at various engine brake powers such as 1.08, 2.17, 3.26, 4.34 , and $5.43 \mathrm{~kW}$. The engine speed was set at 1500 $\mathrm{rpm}$. Initially, the emission readings for the OEMmanufactured CC were recorded. The OEM consists of two honeycomb substrates: one wash-coated with $\mathrm{Pt}$ and $\mathrm{Pd}$ and the other with Rh. The OEMmanufactured 3-way catalyst CC follows the BS-IV emission norms. Then metal oxide-wash coated ceramic foam filter installed CC (one CC for each metal oxide catalyst) was fitted at the exhaust tailpipe, and the readings were separately recorded for each metal oxide catalyst. At each brake power, fuel consumption and emissions ( $\mathrm{HC}, \mathrm{NOx}$, and $\mathrm{CO}$ ) were noted thrice, and the mean values were used to determine the performance and emission abilities. At the beginning of each measurement, the leftover gases from previous experiments present in the gas analyzer probe were purged completely. Table 2 shows the ranges and accuracy of the measuring devices used for testing.

Table 2 Range and accuracy of the measuring device

\begin{tabular}{lllll}
\hline S.No. & Device & Measured & Range & Accuracy \\
\hline 1 & Load cell & Load & $0-100 \mathrm{~kg}$ & $\pm 0.2 \mathrm{~kg}$ \\
2 & Magnetic pickup sensor & Speed & $0-5000 \mathrm{rpm}$ & $\pm 10 \mathrm{rpm}$ \\
3 & Electronic weighing machine & Fuel consumption & $0-10 \mathrm{~kg}$ & $\pm 0.001 \mathrm{~kg}$ \\
4 & NETEL multi-gas analyzer & $\mathrm{CO}$ & $0-10 \% \mathrm{vol}$. & $\pm 0.02 \%$ \\
& & $\mathrm{HC}$ & $0-2000 \mathrm{ppm}$ & $\pm 5 \mathrm{ppm}$ \\
& & $\mathrm{NO}_{\mathrm{x}}$ & $0-5000 \mathrm{ppm}$ & $\pm 20 \mathrm{ppm}$ \\
\hline
\end{tabular}

\subsection{Calculations}

The derived parameters, such as BTE, $\mathrm{CO}, \mathrm{HC}$, and $\mathrm{NO}_{\mathrm{x}}$ conversion efficiencies were calculated from the measured parameters, such as fuel consumption, $\mathrm{CO}$, $\mathrm{HC}$ and $\mathrm{NO}_{\mathrm{x}}$ emission, respectively, using the following formulae:

$\mathrm{BTE}=\frac{\text { Brake Power }}{\mathrm{CV} \mathrm{X} \mathrm{m}_{\mathrm{f}}} \times 100(\%)$,

Where $\mathrm{CV}$ and $\mathrm{m}_{\mathrm{f}}$ indicate the calorific value $(\mathrm{kJ} / \mathrm{kg})$ and mass flow rate of fuel $(\mathrm{kg} / \mathrm{s})$, respectively.

CO Conversion Efficiency $=\frac{\mathrm{CO}_{\mathrm{WOC}^{-}} \mathrm{CO}_{\mathrm{Wc}}}{\mathrm{CO}_{\mathrm{WOC}}} \times$ $100(\%)$

Here, $\mathrm{CO}_{\mathrm{WOC}}$ and $\mathrm{CO}_{\mathrm{WC}}$ denote the $\mathrm{CO}$ emission measured in the presence and absence of CC (\% volume), respectively.

\section{HC Conversion Efficiency =} $\frac{\mathrm{HC}_{\mathrm{WOC}}-\mathrm{HC}_{\mathrm{WC}}}{\mathrm{HC}_{\mathrm{WOC}}} \times 100(\%)$

Here, $\mathrm{HC}_{\mathrm{WOC}}$ and $\mathrm{HC}_{\mathrm{WC}}$ denote the $\mathrm{HC}$ emission measured in the presence and absence of $\mathrm{CC}$ (ppm), respectively.

$\mathrm{NO}_{\mathrm{x}}$ Conversion Efficiency $=$

$\frac{\mathrm{NO}_{\mathrm{xWOC}}-\mathrm{NO}_{\mathrm{XWC}}}{\mathrm{NO}_{\mathrm{XWOC}}} \times 100(\%)$

Here, $\mathrm{NO}_{\mathrm{xWOC}}-\mathrm{NO}_{\mathrm{x} W C}$ denotes the $\mathrm{NO}_{\mathrm{x}}$ emission measured in the presence and absence of $\mathrm{CC}(\mathrm{ppm})$.
The estimated values of BTE, $\mathrm{CO}, \mathrm{HC}$, and $\mathrm{NO}_{\mathrm{x}}$ conversion efficiencies with respect to various engine brake powers for Original Equipment Catalytic Converter (WOECC) containing honeycomb monolith as a substrate and supported with $\mathrm{Pt}$ and $\mathrm{Pd}$ as catalyst materials, and $\mathrm{TiO}_{2}, \mathrm{Al}_{2} \mathrm{O}_{3}$, and $\mathrm{CuO}$ metal oxidecoated ceramic foam filters are presented in AppendixI.

\section{Results}

4.1Brake thermal efficiency (BTE)

Figure 8 compares the BTE recorded for WOECC and that recorded for the ceramic foam filter wash coated with $\mathrm{TiO}_{2}, \mathrm{Al}_{2} \mathrm{O}_{3}$, and $\mathrm{CuO}$. The BTE increases with an increase in the engine brake power. This is due to the improvement in the engine in-cylinder operating conditions which enhances the rate of fuel evaporation and improves the air-fuel mixing process. This results in better combustion.

The BTE recorded for the ceramic foam filter as a substrate was lower than that recorded for WOECC. At $5.43 \mathrm{~kW}$, the BTEs of the ceramic foam filter washcoated with $\mathrm{Al}_{2} \mathrm{O}_{3}, \mathrm{CuO}$, and $\mathrm{TiO}_{2}$ were $31.6 \%$, $30.2 \%$, and $29.2 \%$, respectively. The values were lower than the value obtained using the honeycomb substrate [33.14\%]. This can be attributed to a comparatively higher drop in pressure across the ceramic foam substrate (compared to that observed across the honeycomb monolith substrate). The high drop in pressure could be attributed to a greater flow 
resistance offered by the former in comparison to the latter $[15,21]$. This resulted in higher back pressure, which pushed the exhaust gases back to the engine side and increased the contents of the diluent gas inside the engine cylinder. This increase in the amounts of the diluents (exhaust gases) resulted in a loss in engine power. A slight increase in fuel consumption, resulting in the reduction in BTE for the ceramic foam filters, was observed. Under conditions of minimum BP, the BTEs recorded for $\mathrm{Al}_{2} \mathrm{O}_{3}, \mathrm{CuO}$, and $\mathrm{TiO}_{2}$ were $6.9 \%$, $14.9 \%$, and $24.7 \%$ lesser than the BTE recorded for the honeycomb monolith, respectively.

It was also observed that BTE varied with the type of metal oxides used as the catalyst material in the ceramic foam filter. The trend of BTEs recorded with the metal oxides was determined: $\mathrm{Al}_{2} \mathrm{O}_{3}>\mathrm{CuO}>\mathrm{TiO}_{2}$. The same trend was observed under conditions of all the tested engine brake powers. At $1.08 \mathrm{~kW}$, the BTEs of the ceramic foam filter wash coated with $\mathrm{Al}_{2} \mathrm{O}_{3}$, $\mathrm{CuO}$, and $\mathrm{TiO}_{2}$ were $15.1 \%, 13.8 \%$, and $12.2 \%$, respectively. This can be attributed to the variation in the catalytic activities of the different metal oxide catalysts. The trend in the catalytic activities was determined: $\mathrm{Al}_{2} \mathrm{O}_{3}<\mathrm{CuO}<\mathrm{TiO}_{2}[34,35]$. A higher catalytic activity increases the flow resistance across the ceramic substrate, which in turn increases the pressure drop and reduces the $\mathrm{BTE}$ of $\mathrm{CuO}$ and $\mathrm{TiO}_{2}$ catalysts. The BTEs recorded for these catalysts were lower than that recorded for $\mathrm{Al}_{2} \mathrm{O}_{3}$ wash coated ceramic foam substrate.

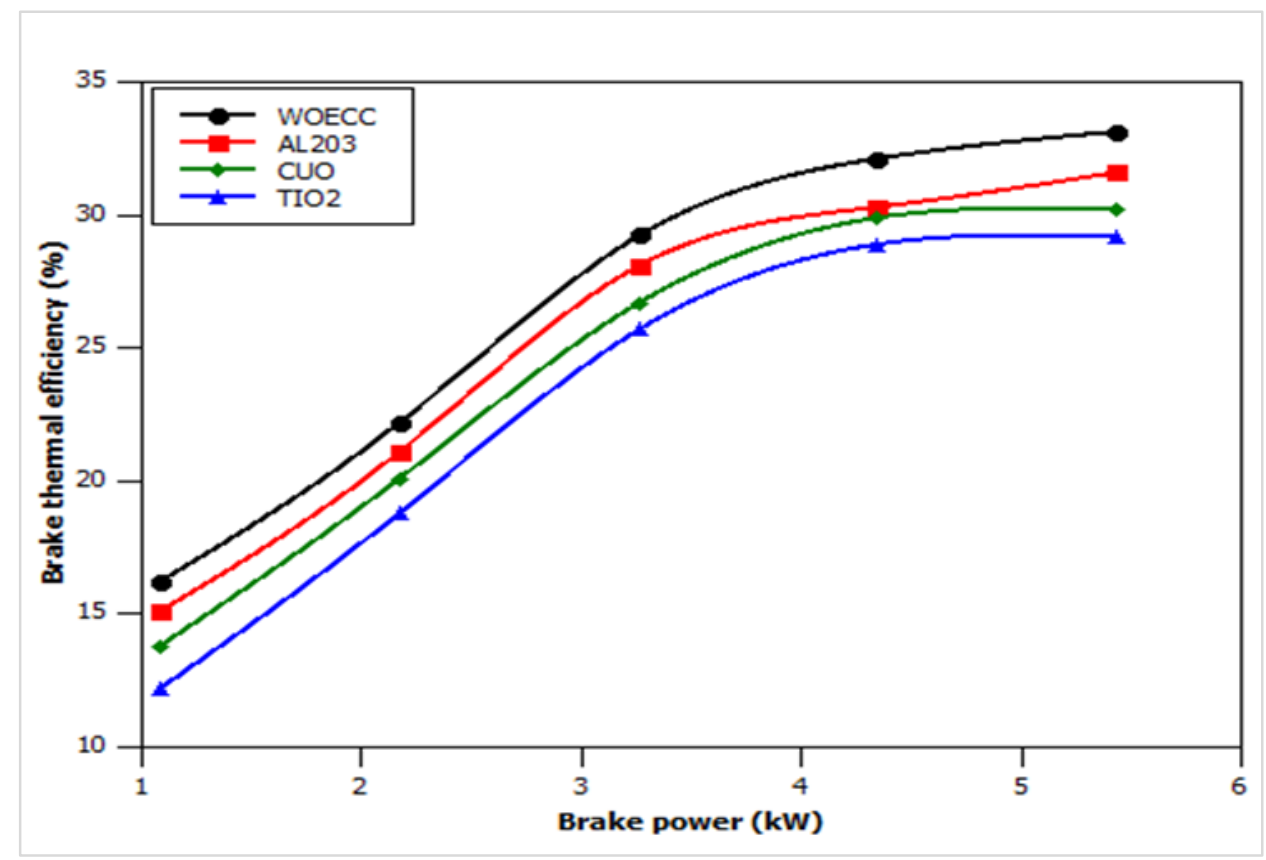

Figure 8 Comparison of BTE WOECC and ceramic foam filter wash coated with different oxide-based catalysts

\subsection{CO conversion efficiency}

The CO conversion efficiencies recorded for WOECC and the ceramic foam filter substrate wash coated with metal oxides are presented in Figure 9. A similar trend was observed for both CCs. The CO emission conversion efficiency decreased gradually with an increase in the brake power. At $1.08 \mathrm{~kW}$, the $\mathrm{CO}$ conversion efficiencies recorded for WOECC and $\mathrm{TiO}_{2}$-coated ceramic foam installed CC were $89 \%$ and $95 \%$, respectively, whereas, at $5.43 \mathrm{~kW}$, the values were $80 \%$ and $88 \%$, respectively. This is due to a slight increase in an equivalence ratio (i.e., the mixture at higher loads is richer than the mixture at lower loads). This results in low oxygen levels in the exhaust under 1041 conditions of high loads $[2,5]$. This, in turn, lowers the catalytic activity and results in lesser conversion efficiency under conditions of high loads.

Compared to WOECC, the metal oxide wash-coated ceramic foam substrate shows higher $\mathrm{CO}$ conversion efficiency. At maximum brake power, the $\mathrm{CO}$ conversion efficiencies across the honeycomb monolith ceramic foam filter coated with $\mathrm{Al}_{2} \mathrm{O}_{3}, \mathrm{CuO}$, and $\mathrm{TiO}_{2}$ were $80 \%, 86 \%, 87 \%$, and $88 \%$ respectively. At minimum power, it was $89 \%, 92 \%, 93 \%$, and $95 \%$, respectively. This can be attributed to the fact that the structure of the ceramic foam induces turbulent flow across the foam filter, whereas, inside the honeycomb, 
the flow is laminar [11]. The turbulent flow enhances the heat and mass transfer characteristics, resulting in the better activation of the ceramic foam filter compared to the honeycomb substrate [19, 36, 37]. Under conditions of turbulent flow, the species mixing ability is enhanced. Subsequently, the contact area for the exhaust gas species with the substrate increases. This leads to higher conversion rates in the presence of ceramic foam filters. Even though for the same volume, ceramic foam filter exhibits a lesser surface area than the honeycomb structure, the turbulent flow inside the former increases the conversion rates compared to the latter.

It was observed that the differences between the $\mathrm{CO}$ conversion efficiencies recorded for WOECC and metal oxide wash-coated ceramic foam substrates were higher under conditions of elevated engine loads than those recorded under conditions of lesser loads (Figure 9). This is because, compared to the Pt and Pd catalysts, the efficiencies of the metal oxide catalysts are higher at higher temperatures [32]. An increase in the engine power results in an increase in the exhaust gas temperature $[30,31]$. Thus the difference in conversion efficiency is higher under conditions of higher engine brake power.

Among the three metal oxide-coated ceramic filters, the $\mathrm{TiO}_{2}$ wash-coated ceramic foam filter exhibits the maximum $\mathrm{CO}$ conversion efficiency. This is followed by $\mathrm{CuO}$ and $\mathrm{Al}_{2} \mathrm{O}_{3}$. At $1.08 \mathrm{~kW}$, the $\mathrm{CO}$ conversion efficiency recorded for $\mathrm{TiO}_{2}$ is higher by approximately $2 \%$ and $3 \%$ compared to $\mathrm{CuO}$ and $\mathrm{Al}_{2} \mathrm{O}_{3}$, respectively. At $5.43 \mathrm{~kW}$, it is higher by approximately $1 \%$ and $2 \%$, respectively. This is because $\mathrm{TiO}_{2}$ exhibits better catalytic activity in comparison to the other two metal oxides. The major reason is that titanium has a greater affinity for oxygen compared to the other two metals [38]. Hence, oxygen is conveniently adsorbed onto the active sites formed by $\mathrm{TiO}_{2}$, resulting in better oxidation of $\mathrm{CO}$. Hence, the conversion rate is high for the $\mathrm{TiO}_{2}$ wash-coated ceramic foam filter.

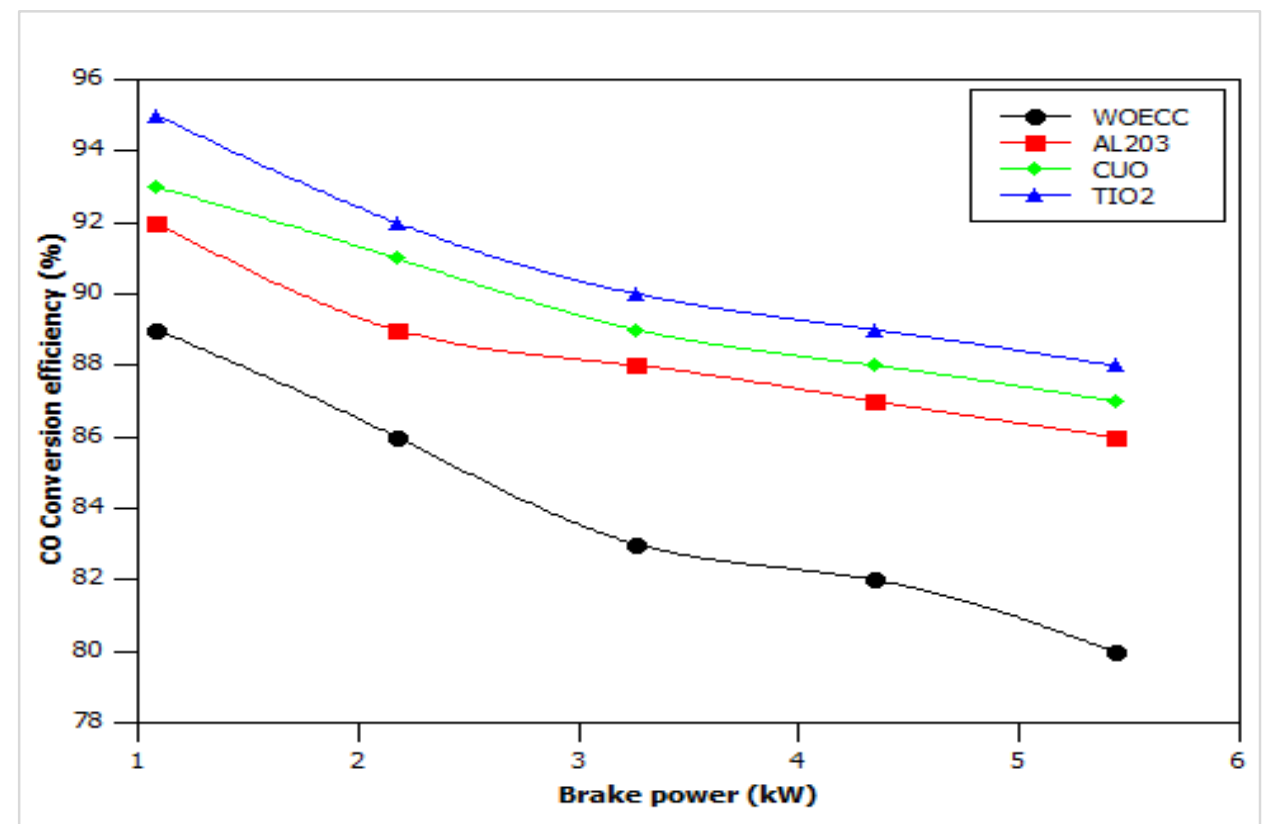

Figure 9 CO conversion efficiencies recorded for WOECC and different oxide catalyst wash coated ceramic foam filters

\subsection{HC conversion efficiency}

Figure 10 depicts the trend of the $\mathrm{HC}$ conversion efficiency exhibited by WOECC and metal oxide wash-coated ceramic foam filters. It was observed that the HC conversion efficiency, increased gradually with the increase in the brake power. Similar trends were exhibited by both honeycomb and ceramic foam substrates. The reason is that an increase in the brake power results in an increase in the exhaust gas temperature. This, in turn, enhances the catalytic activity and results in increased conversion efficiency [25]. 
When compared to the honeycomb substrate, the ceramic foam exhibits higher conversion efficiency as higher turbulence are induced when the exhaust gas flows through the ceramic foam $[15,20]$. The effect of turbulence on conversion is discussed in the aforementioned Section 4.2. At $5.43 \mathrm{~kW}$, the HC conversion efficiencies across the honeycomb monolith, ceramic foam filter coated with $\mathrm{Al}_{2} \mathrm{O}_{3}, \mathrm{CuO}$, and $\mathrm{TiO}_{2}$ were $79 \%, 92 \%, 93 \%$, and $95 \%$, respectively, whereas, at $1.08 \mathrm{~kW}$, the efficiencies were $70 \%, 85 \%, 87 \%$, and $88 \%$, respectively. The use of metal oxides helps increase the conversion efficiency because effective oxidation of unburned hydrocarbons can be achieved in their presence [29, 30]. The metal oxides form rich, acidic sites and inherent oxygen present in them, contributing to the oxidation process [32]. Thus, a high HC conversion efficiency can be achieved using metal oxides as catalyst materials.

It is also inferred from Figure 10 that among all the metal oxides, the maximum conversion efficiency is recorded for $\mathrm{TiO}_{2}$. As titanium has a greater affinity toward oxygen [38,39], it can potentially help in faster oxygen adsorption on the active catalytic sites where the oxidation reaction takes place. This factor also contributes to the enhancement in the rate of oxidation and helps in achieving high conversion efficiency.

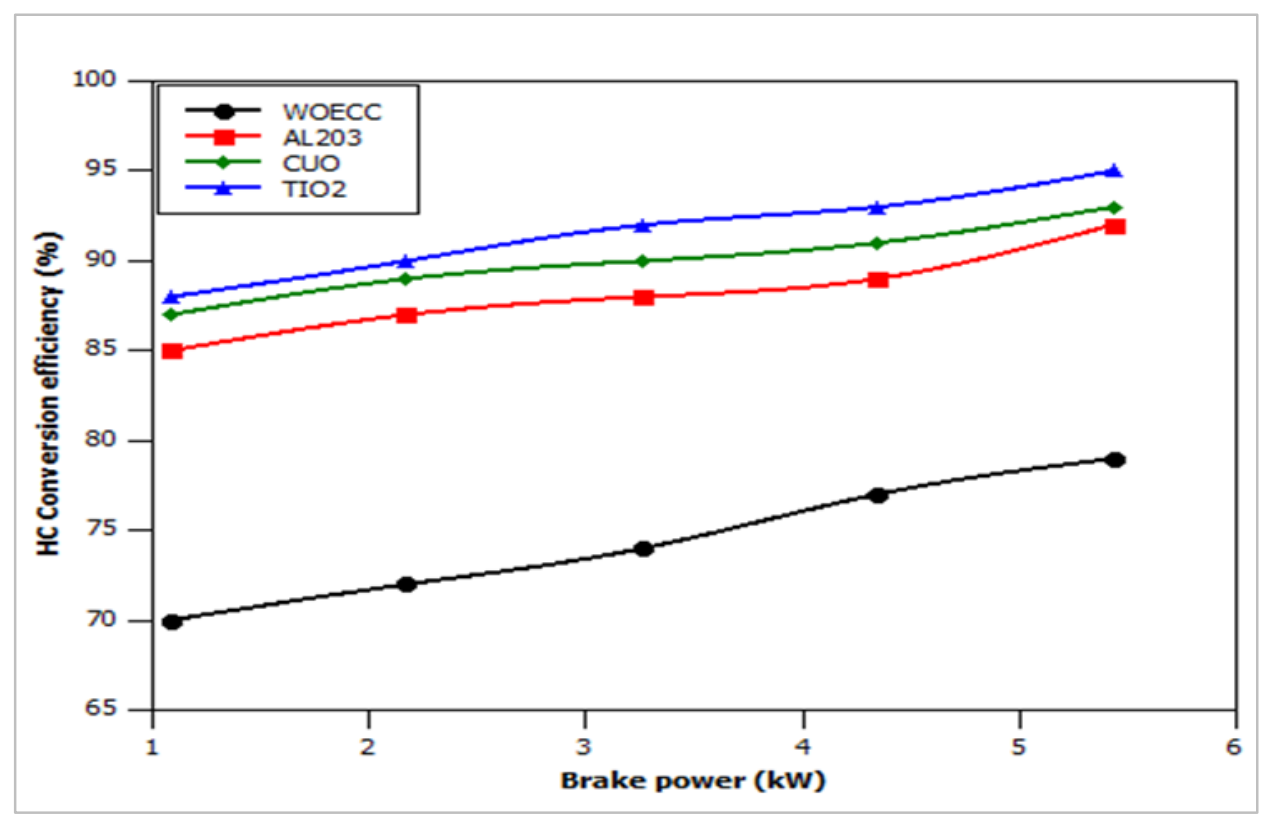

Figure $10 \mathrm{HC}$ conversion efficiencies recorded for WOECC and metal oxide catalyst wash coated ceramic foam filters

\subsection{NOx conversion efficiency}

Figure 11 shows the $\mathrm{NO}_{\mathrm{x}}$ conversion efficiencies recorded for WOECC and metal oxide-coated ceramic foam filters. The $\mathrm{NO}_{\mathrm{x}}$ conversion efficiency increases with an increase in the brake power for both honeycomb and ceramic foam substrates. This can be attributed to the increase in the temperature of the exhaust, which enhances the catalytic activity across the substrate $[30,31]$. The metal oxide coated ceramic foam can help reduce NOx emissions. This can be attributed to the excellent redox property of the metal oxides [32]. Also, the turbulence created by the ceramic structure played a vital role in the reduction of $\mathrm{NO}_{\mathrm{x}}$ emission. The turbulence enhances the rate of contact and heat transfer characteristics, which help activate the entire foam bed in a short period. These results in an improved emission conversion rate and better performance of the foam filter. The conversion efficiency exhibited by the metal oxide-coated ceramic foam is slightly higher than that recorded for WOECC. At $5.43 \mathrm{~kW}$, the $\mathrm{NO}_{\mathrm{x}}$ conversion efficiencies for WOECC, $\mathrm{Al}_{2} \mathrm{O}_{3}, \mathrm{CuO}$, and $\mathrm{TiO}_{2}$ coated ceramic foam were $59 \%, 61 \%, 63 \%$, and $65 \%$, respectively. At $1.08 \mathrm{~kW}$, the $\mathrm{NO}_{\mathrm{x}}$ conversion efficiencies for $\mathrm{Al}_{2} \mathrm{O}_{3}, \mathrm{CuO}$, and $\mathrm{TiO}_{2}$ coated ceramic foam were $4.3 \%, 8.6 \%$, and $10.8 \%$, respectively, higher than that recorded for WOECC.

The maximum conversion efficiency was exhibited by $\mathrm{TiO}_{2}$. The Rutile phase of $\mathrm{TiO}_{2}$ is stable at very high temperatures. This helps catalyze the decomposition of $\mathrm{NO}$ to $\mathrm{N}_{2}$ and $\mathrm{O}[39,40]$. Though metal oxide wash- 
coated foam filter helps reduce $\mathrm{NO}_{\mathrm{x}}$ emission, the level of emission achieved post treatment is still higher than the current emission standards (BS-VI norms). The $\mathrm{NO}_{\mathrm{x}}$ conversion efficiency can be improved further if the catalysts are used in combination with the
Selective Catalytic Reduction (SCR) system. Complete list of abbreviations is shown in Appendix II.

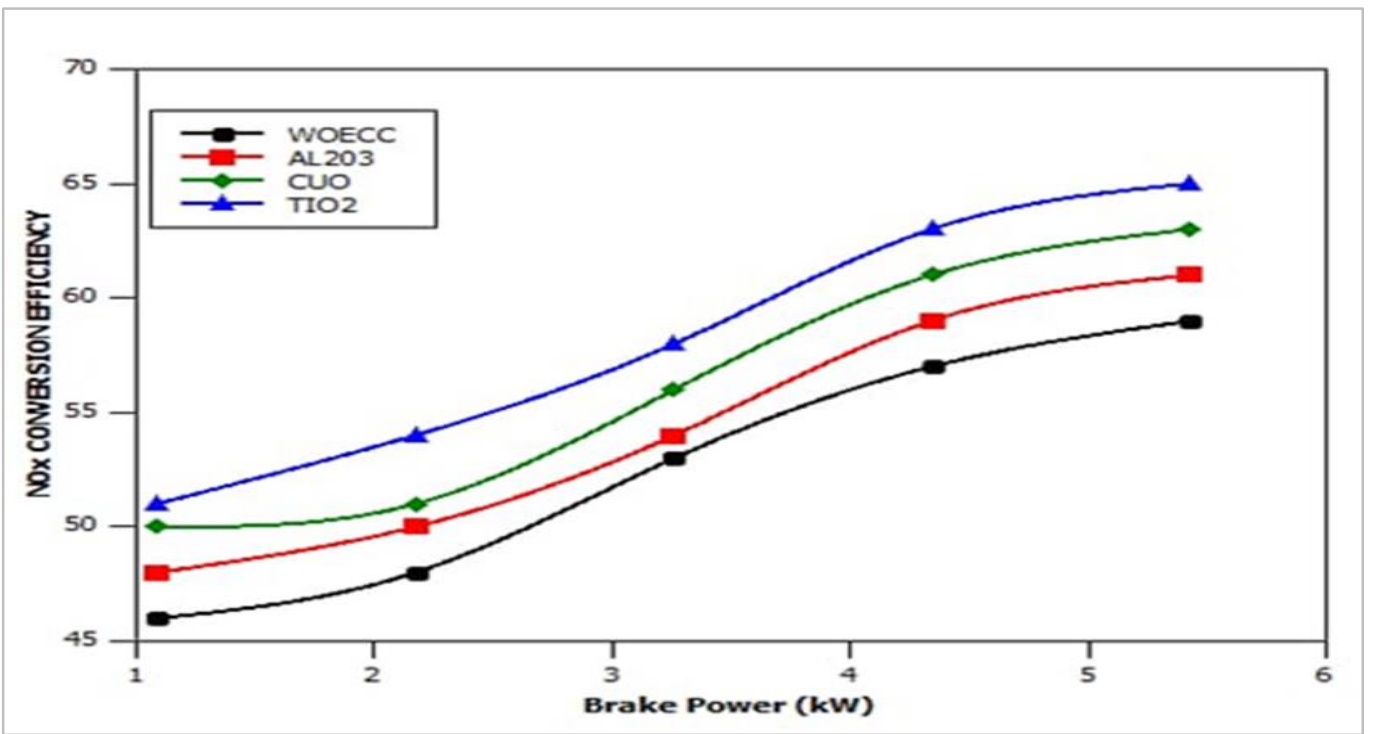

Figure $11 \mathrm{NO}_{\mathrm{x}}$ conversion efficiencies recorded for WOECC and oxide catalyst wash coated ceramic foam filter

\section{Discussion}

It was observed that the ceramic foam filters (used as converter substrates) performed better than the conventional honeycomb monoliths irrespective of the engine brake power. This can be attributed to the fact that an exchange of momentum perpendicular to the direction of flow induces turbulence within the ceramic foam filters, enhancing the heat and mass transfer characteristics. The enhanced characteristics can be attributed to the significantly higher Sherwood and Nussult numbers recorded in these cases (compared to the numbers recorded during the laminar flow inside honeycomb substrate). Homogeneous thermal and chemical loads inside the ceramic foam filters are generated under these conditions. The turbulence helps in better mixing of species, which facilitates the complete oxidation of $\mathrm{HC}$ and $\mathrm{CO}$. It also helps achieve high conversion rates.

The emission conversion efficiency recorded for the ceramic foam filters was higher than that recorded for the honeycomb monolith substrate. The metal oxides were better catalyst materials than the conventional catalyst materials ( $\mathrm{Pd}, \mathrm{Pt}$, and $\mathrm{Rh}$ ) under the testing conditions. The BTEs recorded for the ceramic foam filters were lower than those recorded for the honeycomb monolith. This can be attributed to a higher pressure drop, attributable to the higher flow 1044 resistance offered by the former in comparison to the latter. The structure of the ceramic foam should be modified to reduce the extent of pressure drop. Structural modifications of the ceramic foams are being simulated by numerous researchers.

The key findings are presented as follows:

- Metal oxide-coated ceramic foam offers high HC, $\mathrm{CO}$, and $\mathrm{NO}_{\mathrm{x}}$ emission conversion efficiencies at the expense of engine BTE.

- The maximum conversion efficiency is achieved using $\mathrm{TiO}_{2}$, followed by $\mathrm{CuO}$ and $\mathrm{Al}_{2} \mathrm{O}_{3}$.

The potential limitations of this study are:

1. The performance and emission tests were limited to a stationary engine. The emission test should be performed during driving cycles, which would simulate the real road driving conditions.

2. The conversion efficiencies of the foams were tested after the light-off temperature was reached. The performances should be studied under cold conditions.

3. The filters got clogged with the particulate matter when the engine was run using ceramic foam filters that were $\leq 10$ PPI. This resulted in severe engine backpressure, and subsequently, the engine stopped. 


\section{Conclusion and future work}

The ceramic foam filters were wash coated with different metal oxides such as $\mathrm{Al}_{2} \mathrm{O}_{3}, \mathrm{CuO}$, and $\mathrm{TiO}_{2}$, which were used as catalyst materials. The washcoated ceramic foam filters were installed in the inhouse fabricated $\mathrm{CC}$ casing. The performance of the engine fabricated with ceramic foam $\mathrm{CC}$ and the $\mathrm{CO}$ and $\mathrm{HC}$ emission conversion efficiencies was tested for a diesel engine. The results were compared with the results obtained with the OEM-manufactured CC that was installed with honeycomb monolith as the substrate and wash-coated with the conventionally used Pd and Pt metal catalysts. The results obtained from the experiments have been summarized as follows:

The BTEs recorded in the engine fabricated with $\mathrm{Al}_{2} \mathrm{O}_{3}, \mathrm{CuO}$, and $\mathrm{TiO}_{2}$ wash coated ceramic foam filters were $31.6 \%, 30.2 \%$, and $29.2 \%$, respectively. The values were lower than the BTE values recorded for the OEM-manufactured CC under conditions of the maximum engine load. The BTE recorded for the OEM-manufactured CC was $33.14 \%$.

The CO conversion efficiencies recorded for the CCs fabricated using $\mathrm{Al}_{2} \mathrm{O}_{3}, \mathrm{CuO}$, and $\mathrm{TiO}_{2}$ coated ceramic foams at fill load were $86 \%, 87 \%$, and $88 \%$, respectively, at $5.43 \mathrm{~kW}$. The values were higher than the values recorded for the $\mathrm{Pd}$ and Pt-coated honeycomb monolith (80\%). The HC conversion efficiency of the ceramic coated with metal oxides was higher than the HC conversion efficiency of the OEMmanufactured $\mathrm{CC}$. The $\mathrm{HC}$ conversion efficiencies of the OEM-manufactured $\mathrm{CC}, \mathrm{Al}_{2} \mathrm{O}_{3}, \mathrm{CuO}$, and $\mathrm{TiO}_{2}$ coated ceramic foam were $79 \%, 92 \%, 93 \%$, and $95 \%$, respectively, under conditions of full load. The $\mathrm{NO}_{\mathrm{x}}$ conversion efficiency recorded for the metal oxidecoated ceramic foam filter was higher than that recorded for the honeycomb monolith substrate coated with rhodium. It can be concluded that a ceramic foam filter with metal oxide coating can be potentially used to replace the conventionally used noble metal-coated honeycomb monolith when the pressure drop across the foam (resulting in reduced BTE) is low.

The sustainability and efficiency of the ceramic foam filters at long hours of engine run is to be studied in the future to find out its limitations and probability of their applicability in commercial engines. Also, the catalytic activity of metal oxides at low temperatures should be studied.

Acknowledgment

None.

1045
Conflicts of interest

The authors have no conflicts of interest to declare.

References

[1] Kumar BR, Saravanan S, Rana D, Nagendran A. A comparative analysis on combustion and emissions of some next generation higher-alcohol/diesel blends in a direct-injection diesel engine. Energy Conversion and Management. 2016; 119:246-56.

[2] Loganathan M, Madhavan VM, Balasubramanian KA, Thanigaivelan V, Vikneswaran M, Anbarasu A. Investigation on the effect of diethyl ether with hydrogen-enriched cashew nut shell (CNS) biodiesel in direct injection (DI) diesel engine. Fuel. 2020.

[3] Raj VM, Subramanian LG, Thiyagarajan S, Geo VE. Effects of minor addition of aliphatic (1-pentanol) and aromatic (benzyl alcohol) alcohols in simarouba glauca-diesel blend fuelled CI engine. Fuel. 2018; 234:934-43.

[4] Veerabadran V, Veerasigamani M, Shanmugam S. Effect of carbon nanotube material in diesel engine with exhaust gas recirculation. Energy Sources, Part A: Recovery, Utilization, and Environmental Effects. 2020.

[5] Thiruvenkatachari S, Saravanan CG, Geo VE, Vikneswaran M, Udayakumar R, Aloui F. Experimental investigations on the production and testing of azolla methyl esters from azolla microphylla in a compression ignition engine. Fuel. 2021.

[6] Nandakumar C, Raman V, Saravanan CG, Vikneswaran M, Yadav SP, Thirunavukkarasu M. Effect of nozzle hole geometry on the operation of kapok biodiesel in a diesel engine. Fuel. 2020.

[7] Singh N, Mishra T, Banerjee R. Emissions inventory for road transport in India in 2020: framework and post facto policy impact assessment. Environmental Science and Pollution Research. 2021.

[8] Williams M, Minjares R. A technical summary of Euro 6/VI vehicle emission standards. International Council for Clean Transportation (ICCT), Washington, DC. 2016.

[9] Muthuswamy S, Veerasigamani M. Impact of secondary fuel injector in various distance on direct injection diesel engine using acetylene-bio diesel in reactivity controlled compression ignition mode. Energy Sources, Part A: Recovery, Utilization, and Environmental Effects. 2020.

[10] Yildiz I, Caliskan H, Mori K. Effects of cordierite particulate filters on diesel engine exhaust emissions in terms of pollution prevention approaches for better environmental management. Journal of Environmental Management. 2021.

[11] https://ceramics.org/ceramic-tech-today/empa-claimsnew-ceramic-foam-approach-advances-diesel-filterstructure-2. Accessed 20 July 2021.

[12] www.sciencedaily.com/releases/2013/04/1304251325 26.htm. Accessed 20 July 2021.

[13] Panayotis D, Christian B. Ceramic foams for automotive catalyst substrate applications. European 
Ele-Drive conference, international advanced mobility forum geneva, Switzerland.2008.

[14] Dimopoulos P, Thurnheer T, Bach C. High efficiency exhaust aftertreatment: purposeful application of ceramic foams, MTZ. In motorentechnische zeitschrift, conference " the drive of tomorrow ", Munich, Germany 2008.

[15] Bach C, Dimopoulos EP. Ceramic foam catalyst substrates for diesel oxidation catalysts: pollutant conversion and operational issues. SAE Technical Paper. 2011.

[16] Cho G, Choi H, Jeong Y, Kim H, An S, Jeong B, et al. $\mathrm{PM}$ reduction performance and regeneration characteristics of catalyzed metal foam filters for a $3 \mathrm{~L}$ diesel passenger vehicle. SAE Technical Paper. 2007.

[17] Tsinoglou DN, Eggenschwiler PD, Thurnheer T, Hofer P. A simplified model for natural-gas vehicle catalysts with honeycomb and foam substrates. Proceedings of the Institution of Mechanical Engineers, Part D: Journal of Automobile Engineering. 2009; 223(6):819-34.

[18] Setiabudi A, Makkee M, Moulijn JA. An optimal usage of NOx in a combined Pt/ceramic foam and a wall-flow monolith filter for an effective $\mathrm{NO}_{\mathrm{x}}$-assisted diesel soot oxidation. SAE Technical Paper. 2003.

[19] Dimopoulos P, Bach C, Vogt UF, Herrmann K. Ceramic foams as catalyst substrates: pre-catalyst application homogenising the exhaust flow upstream of aftertreatment devices. SAE Technical Paper. 2007:115.

[20] Eggenschwiler PD, Tsinoglou DN, Seyfert J, Bach C, Vogt U, Gorbar M. Ceramic foam substrates for automotive catalyst applications: fluid mechanic analysis. Experiments in Fluids. 2009; 47:209-22.

[21] Amirnordin SH, Rahman HA, Nor NA, Hudin AS, Rahmat N, Ali MF, et al. Pressure drop characteristic of alumina-zeolite porous ceramic filter and its effects in engine performance. UTHM Institutional Repository 2010.

[22] Garrido GI, Patcas FC, Lang S, Kraushaar-czarnetzki B. Mass transfer and pressure drop in ceramic foams: a description for different pore sizes and porosities. Chemical Engineering Science. 2008; 63(21):5202-17.

[23] Hideki AB. Current status and future of the car exhaust catalyst. Quarterly Review. 2011.

[24] Babu AM, Saravanan CG, Vikneswaran M, Geo VE, Sasikala J, Josephin JF, et al. Analysis of performance, emission, combustion and endoscopic visualization of micro-arc oxidation piston coated SI engine fuelled with low carbon biofuel blends. Fuel. 2021.

[25] Shukla PC, Gupta T, Labhsetwar NK, Agarwal AK. Development of low cost mixed metal oxide based diesel oxidation catalysts and their comparative performance evaluation. RSC Advances. 2016; 6(61):55884-93.

[26] Ciambelli P, Matarazzo G, Palma V, Russo P, Borla EM, Pidria MF. Reduction of soot pollution from automotive diesel engine by ceramic foam catalytic filter. Topics in Catalysis. 2007; 42:287-91.

[27] Makwana NR, Amin CM, Dabhi SK. Development and performance analysis of nickel based catalytic converter. International Journal of Advanced Engineering Technology. 2013; 4(II):10-13.

[28] Kalam MA, Masjuki HH, Redzuan M, Mahlia TM, Fuad MA, Mohibah M, et al. Development and test of a new catalytic converter for natural gas fuelled engine. Sadhana. 2009; 34:467-81.

[29] Venkatesan SP, Uday DS, Hemant BK, Goud KR, Kumar GL, Kumar KP. IC engine emission reduction by copper oxide catalytic converter. In IOP conference series: materials science and engineering 2017 (pp.1-9). IOP Publishing.

[30] Chauhan HJ. Highly efficient and low cost substance type catalytic convertor for petrol engine. International Journal of Innovative Trends in Engineering. 2015; $4(2): 62-8$.

[31] Guan B, Zhan R, Lin H, Huang Z. Review of state of the art technologies of selective catalytic reduction of NOx from diesel engine exhaust. Applied Thermal Engineering. 2014; 66(1-2):395-414.

[32] Jia C, Gao J, Huang KW, Jose V, Thepsithar P, Lee JM. Selective catalytic reduction of NOx in marine engine exhaust gas over supported transition metal oxide catalysts. Chemical Engineering Journal. 2021.

[33] Aalam CS, Saravanan CG, Samath CM. Reduction of diesel engine emissions using catalytic converter with nano aluminium oxide catalyst. International Journal for Research in Emerging Science and Technology. 2015; 2(7):17-22.

[34] Shen B, Liu T, Zhao N, Yang X, Deng L. Iron-doped $\mathrm{Mn}-\mathrm{Ce} / \mathrm{TiO}_{2}$ catalyst for low temperature selective catalytic reduction of $\mathrm{NO}$ with $\mathrm{NH}_{3}$. Journal of Environmental Sciences. 2010; 22(9):1447-54.

[35] Husnain N, Wang E, Li K, Anwar MT, Mehmood A, Gul M, et al. Iron oxide-based catalysts for lowtemperature selective catalytic reduction of NOx with $\mathrm{NH}_{3}$. Reviews in Chemical Engineering. 2019; 35(2):239-64.

[36] Giani L, Groppi G, Tronconi E. Heat transfer characterization of metallic foams. Industrial \& Engineering Chemistry Research. 2005; 44(24):907885.

[37] Giani L, Groppi G, Tronconi E. Mass-transfer characterization of metallic foams as supports for structured catalysts. Industrial \& Engineering Chemistry Research. 2005; 44(14):4993-5002.

[38] Cheng Y, Oleszek S, Shiota K, Oshita K, Takaoka M. Comparison of sewage sludge mono-incinerators: mass balance and distribution of heavy metals in step grate and fluidized bed incinerators. Waste Management. 2020; 105:575-85.

[39] Meerson GA, Segorcheanu T. The affinity of niobium for oxygen. Soviet Atomic Energy. 1963; 13:1230-3.

[40] Khoiron AM, Anis S, Masugino SS, Fajri SN. Catalytic converter based on titanium oxide $\left(\mathrm{TiO}_{2}\right)$ to reduce the emission of carbon monoxide and hydrocarbon in exhaust gas of motor vehicles. In proceedings of the 7th engineering international conference on education, concept and application on green technology 2018 (pp. 15-20). 


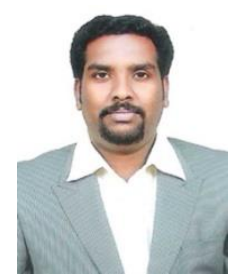

M. Premnath, is a part time research scholar in Annamali university and working as Assistant professor in the same university. He has completed his under graduation and post graduation in Annamali university. He has more than 14 years of teaching experience. His research center around Emission control in Internal Combustion Engines.

Email: amvpremnath@gmail.com

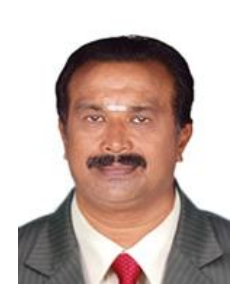

G. Murugan, Professor of Mechanical Engineering, Annamalai University, Annamalainagar, Tamilnadu, India. He has completed his Doctor of Philosophy from the same Institution. He has 23 years of teaching experience. Presently two research scholars are doing their reserch under his guidance and support. He has published more than 20 research papers in various reputed national and International journals. He is specialized in Fatigue Investigation and Automobile Engineering. Email: gmuruganlink@gmail.com

Appendix I

Observation

Table 3 Brake power Vs brake thermal efficiency

\begin{tabular}{lllll}
\hline & \multicolumn{3}{c}{ Brake thermal efficiency } \\
\hline BP & WOECC & $\mathbf{A l}_{\mathbf{2}} \mathbf{O}_{\mathbf{3}}$ & $\mathbf{C U O}$ & $\mathbf{T i O}_{\mathbf{2}}$ \\
\hline 1.08 & 16.22 & 15.1 & 13.8 & 12.2 \\
\hline 2.17 & 21.1 & 20.1 & 18.8 \\
\hline 3.26 & 22.2 & 28.1 & 26.7 & 25.7 \\
\hline 4.34 & 29.23 & 30.3 & 29.9 & 28.9 \\
\hline 5.43 & 32.12 & 31.6 & 30.2 & 29.2 \\
\hline
\end{tabular}

Table 4 Brake power Vs Nox conversion efficiency

\begin{tabular}{lllll}
\hline \multicolumn{5}{c}{$\mathbf{N O}_{\mathbf{x}}$ conversion efficiency } \\
\hline $\mathbf{B P}$ & $\mathbf{W O E C C}$ & $\mathbf{A l}_{\mathbf{2}} \mathbf{O}_{\mathbf{3}}$ & $\mathbf{C U O}$ & $\mathbf{T i O}_{\mathbf{2}}$ \\
\hline 1.08 & 46 & 48 & 50 & 51 \\
\hline 2.17 & 50 & 51 & 54 \\
\hline 3.26 & 48 & 54 & 56 & 58 \\
\hline 4.34 & 53 & 59 & 61 & 63 \\
\hline 5.43 & 57 & 61 & 63 & 65 \\
\hline
\end{tabular}

Table 5 Brake power Vs CO conversion efficiency

\begin{tabular}{lllll}
\hline & \multicolumn{2}{c}{ CO conversion efficiency } & $\mathbf{T i O}_{\mathbf{2}}$ \\
\hline $\mathbf{B P}$ & WOECC & $\mathbf{A l}_{\mathbf{2}} \mathbf{O}_{\mathbf{3}}$ & $\mathbf{C U O}$ & 95 \\
\hline 1.08 & 92 & 92 & 93 & 92 \\
\hline 2.17 & 89 & 89 & 91 & 90 \\
\hline 3.26 & 86 & 88 & 89 & 89 \\
\hline 4.34 & 83 & 87 & 88 & 88 \\
\hline 5.43 & 82 & 86 & 87 & \\
\hline
\end{tabular}

Table 6 Brake power Vs HC conversion efficiency

\begin{tabular}{lllll}
\hline \multicolumn{5}{c}{ HC conversion efficiency } \\
\hline BP & WOECC & $\mathbf{A l}_{\mathbf{2}} \mathbf{O}_{\mathbf{3}}$ & $\mathbf{C U O}$ & $\mathbf{T i O}_{\mathbf{2}}$ \\
\hline 1.08 & 70 & 85 & 87 & 88 \\
\hline 2.17 & 87 & 89 & 90 \\
\hline 3.26 & 72 & 88 & 90 & 92 \\
\hline 4.34 & 74 & 89 & 91 & 93 \\
\hline 5.43 & 77 & 92 & 93 & 95 \\
\hline
\end{tabular}


M.Premnath and G.Murugan

Appendix II

\begin{tabular}{lll}
\hline S. No. & Abbreviation & Description \\
\hline 1 & $\mathrm{Al}_{2} \mathrm{O}_{3}$ & Aluminium Oxide \\
\hline 2 & $\mathrm{BTE}$ & Brake Thermal Efficiency \\
\hline 3 & $\mathrm{CaO}$ & Calcium Oxide \\
\hline 4 & $\mathrm{CC}$ & Catalytic Converters \\
\hline 5 & $\mathrm{CO}$ & Carbon Monoxide \\
\hline 6 & $\mathrm{CoO}$ & Cobalt Oxide \\
\hline 7 & $\mathrm{cpsi}$ & Cells per Square Inch \\
\hline 8 & $\mathrm{CRDI}$ & Common Rail Direct Injection \\
\hline 10 & $\mathrm{CuO}$ & Copper Oxide \\
\hline 11 & $\mathrm{DPF}$ & Diesel Particular Filter \\
\hline 12 & $\mathrm{DOC}$ & Diesel Oxidation Catalyst \\
\hline 13 & $\mathrm{ECU}$ & Electronic Control Unit \\
\hline 14 & $\mathrm{HC}$ & Electronic Fuel Injection \\
\hline 15 & $\mathrm{NO}, \mathrm{NO}_{2}, \mathrm{NO}_{\mathrm{x}}$ & Hydrocarbon \\
\hline 16 & $\mathrm{OEM}$ & Oxides of Nitrogen \\
\hline 17 & $\mathrm{Pd}$ & Original \\
\hline 18 & $\mathrm{PPI}$ & Manufacturer \\
\hline 19 & $\mathrm{Pt}$ & Palladium \\
\hline 20 & $\mathrm{Rh}$ & Pores per Inch \\
\hline 21 & $\mathrm{SCR}$ & Platinum \\
\hline 22 & $\mathrm{TiO} \mathrm{F}_{2}$ & Rhodium \\
\hline 23 & $\mathrm{WOECC}$ & Selective Reduction Catalyst \\
\hline & & Titanium Dioxide \\
\hline & & With Oatalytic Converter \\
\hline
\end{tabular}

